\title{
EFEKTIVITAS LEMBAR KEGIATAN SISWA (LKS) MATEMATIKA BERBASIS PENDEKATAN CONTEXTUAL TEACHING AND LEARNING (CTL) POKOK BAHASAN PERBANDINGAN
}

\author{
${ }^{1}$ Tito Gusmiro, ${ }^{2}$ M. Fachruddin S, ${ }^{3}$ Della Maulidiya \\ 1,2,3 Program Studi Pendidikan Matematika JPMIPA FKIP Universitas Bengkulu \\ email : ${ }^{1}$ titogusmiro@gmail.com, ${ }^{2}$ mfachruddin.s@gmail.com, ${ }^{3}$ della.maulidiya@gmail.com
}

\begin{abstract}
Abstrak
Artikel ini ditulis untuk mendeskripsikan Lembar Kegiatan Siswa (LKS) Matematika pendekatan contextual teaching and leraning (CTL) pokok bahasan perbandingan Jenis penelitian ini adalah penelitian pengembangan (Research and Development) dengan langkah-langkah pengembangan diadopsi dari Tim Puslitjaknov. Sampel penelitian pada uji coba 1 yaitu 10 orang siswa kelas VIII SMP Negeri 1 Pondok Kelapa dan pada uji coba 2 yaitu 18 orang siswa kelas VIII $_{c}$ SMP Negeri 1 Pondok Kelapa. Penelitian dilaksanakan pada semester genap tahun ajaran 2016/2017. Instrumen yang digunakan berupa lembar pengamatan aktivitas siswa dan hasil belajar. Kesimpulan dari penelitian ini adalah 3 LKS yang dikembangkan memenuhi kriteria efektif karena memenuhi a). Lembar pengamatan aktivitas siswa menunjukkan efektif, b) Nilai Hasil belajar setiap tes telah memenuhi ketuntasan minimal.
\end{abstract}

kata kunci: penelitian pengembangan, lembar kegiatan siswa, contextual teaching and learning (CTL), perbandingan

\begin{abstract}
This study was aimed to produce Mathematics Student WorkSheet Based on contextual teaching and learning (CTL) approach on comparison. The type of this research was research and development by using development method Tim Puslitjaknov. The sampels of this research on tesdrive 1 were 10 students of grade VIII $I_{B}$ from SMP Negeri 1 Pondok Kelapa and 18 students of grade VIII $I_{c}$ on testdrive 2 from SMP Negeri 1 Pondok Kelapa. This research was done on even semester of academic year. Instrument used were observasion of student activity sheet and test result of learning. The conclution of this research is tree student work sheet it has fullfilled criteria effective because fulfiled a). with student activity sheet with fullfilled criteria effective b). the value of the learning outcomes of each test has met the minimum mastery.
\end{abstract}

keywords: research and development, student worksheet, contextual teaching and learning, comparison

\section{PENDAHULUAN}

Komalasari (2013:1) menyatakan bahwa munculnya pembelajaran kontekstual dilatarbelakangi oleh rendahnya mutu keluaran/hasil pembelajaran yang ditandai dengan ketidakmampuan sebagian besar siswa menghubungkan apa yang telah mereka pelajari dengan cara pemanfaatan pengetahuan tersebut pada saat ini dan di kemudian hari dalam kehidupan siswa. Lestari dan Yudhanegara (2015:38) Menyatakan bahwa contextual teaching and lerning atau pembelajaran kontekstual adalah suatu pembelajaran yang mengupayakan agar siswa dapat menggali kemampuan yang dimilikinya dengan mempelajari konsep-konsep sekaligus menerapkannya denhan dunia nyata disekitar 
lingkungan siswa. Karweit dalam Yamin (2011:194) Menyatakan bahwa pembelajaran kontekstual adalah sebagai pembelajaran yang dirancang agar peserta didik dapat melaksanakan kegiatan dan memecahkan masalah dengan cara yang mencerminkan sifat tugas-tugas seperti di dunia nyata.

Prastowo (2013: 203-204) mengatakan bahwa LKS yakni lembaran-lembaran berisi tugas yang harus dikerjakan oleh pesesrta didik. Lembar kegiatan biasanya berupa pentunjuk atau langkah-langkah untuk meyelesaikan suatu tugas. Dan, tugas tersebut haruslah jelas kompetensi dasar yang akan dicapai. Trianto (2013: 222) Lembar Kegiatan Siswa adalah panduan siswa yang digunakan untuk melakukan kegiatan penyelidikan atau pemecahan masalah. Lembar kegiatan Siswa dapat berupa panduan untuk latihan pengembangan aspek kognitif maupun panduan untuk pengembangan semua aspek pembelajaran dalam bentuk panduan ekspirimen atau demontrasi. Depdiknas (2008:13) menyatakan LKS adalah Lembaranlembaran berisi tugas yang harus dikerjkan peserta didik. Lembaran Kegiatan biasanya berisi petunjuk, langkah-langkah untuk menyelesaikan tugas.

\section{METODE}

\section{Subjek dalam penelitian pengembangan \\ LKS matematika berbasis pendekatan contextual teaching and learning (CTL) ini adalah Siswa-siswi SMP Negeri 1 Pondok Kelapa. dengani menggunakan dua tahapan uji coba yaitu uji coba 1 dan uji coba 2 . Sampel penelitian pada tahapan uji coba 1 yaitu 10 orang siswa kelas $\mathrm{VIII}_{\mathrm{b}}$ SMP Negeri 1 Pondok Kelapa dan pada tahapan uji coba 2 yaitu siswa kelas VIII $_{c}$ SMP Negeri 1 Pondok Kelapa. Penelitian dilaksanakan pada semester genap tahun ajaran 2016/2017.}

Prosedur penelitian pengembangan yang diadopsi dari metode Pusat Penelitian kebijakan dan Inovasi Pendidikan (Tim Puslitjaknov, 2008) yang terdiri dari empat tahapan besar. Dapat dilihat pada tabel berikut.
Tabel 1 prosedur Penelitian penegmbangan oleh Puslitjaknov

\begin{tabular}{|c|c|}
\hline $\begin{array}{l}\text { Tahap } \\
\text { Pengembangan } \\
\text { Puslitjaknov }\end{array}$ & Hasil proses yang didapat \\
\hline $\begin{array}{l}\text { 1. Analisis } \\
\text { Produk } \\
\text { a. Analisis } \\
\text { kurikulum }\end{array}$ & $\begin{array}{l}\text { kurikulum yang digunakan di } \\
\text { SMP Negeri } 1 \text { Pondok Kelapa } \\
\text { adalah kurikulum } 2013 \text {. } \\
\text { Jenis kertas yang digunakan } \\
\text { dalam LKS ini adalah kertas } \\
\text { A4. Jenis kertas ini dipilih } \\
\text { karena ukurannya yang tidak } \\
\text { terlalu besar dan juga tidak } \\
\text { terlalu kecil. Penomoran pada } \\
\text { LKS terstruktur dan konsisten } \\
\text { yang diletakkan di pojok kanan } \\
\text { bawah setiap lembar LKS. } \\
\text { Penomoran ini dibuat untuk } \\
\text { memudahkan siswa mencari } \\
\text { halaman yang diinginkan } \\
\text { misalnya ketika menyelesaikan } \\
\text { soal LKS yang memerlukan } \\
\text { atau berhubungan dengan soal } \\
\text { sebelumny. Dan LKS yang } \\
\text { dibuat sebanmyak } 3 \text { buah. }\end{array}$ \\
\hline 2. Validasi & $\begin{array}{l}\text { pada tahap ini peneliti } \\
\text { melakukan diskusi dengan } \\
\text { validator untuk menelaah } \\
\text { materi, konstruksi, dan bahasa } \\
\text { pada LKS yang dikembangkan. } \\
\text { Setelah itu validaor diminta } \\
\text { untuk mengisi lembar } \\
\text { penyaringan (Screening) atau } \\
\text { lembar pertimbangan ahli. } \\
\text { Hasil dari tahap ini adalah LKS } \\
\text { yang dibuat sudah valid dari segi } \\
\text { materi, konstruksi, dan bahasa. }\end{array}$ \\
\hline 3. Uji coba 1 & $\begin{array}{l}\text { Pada tahap uji coba 1, LKS } \\
\text { diujicobakan kepada } 20 \text { orang } \\
\text { siswa yaitu siswa kelas VIII } \\
\text { SMP Negeri } 1 \text { Pondok Kelapa. } \\
\text { Pada tahap ini tujuannya } \\
\text { adalah untuk menguji } \\
\text { kepraktisan LKS yang } \\
\text { diperoleh dari hasil penilaian } \\
\text { siswa dengan menggunakan } \\
\text { lembar angket respon siswa. } \\
\text { Hasilnya adalah bahawa LKS } \\
\text { yang di uji cobakan sudah } \\
\text { praktis berdasarkan lembar } \\
\text { angket respon siswa. }\end{array}$ \\
\hline
\end{tabular}




\begin{tabular}{|l|l|}
\hline $\begin{array}{l}\text { Tahap } \\
\text { Pengembangan } \\
\text { Puslitjaknov }\end{array}$ & Hasil proses yang didapat \\
\hline 4. Uji Coba & \multicolumn{1}{|c|}{ Pada tahap uji coba 2 } \\
& $\begin{array}{l}\text { LKS diuji cobakan kepada } \\
\text { siswa-siswi kelas VIII SMP } \\
\text { Negeri 1 Pondok Kelapa. Pada } \\
\text { tahap ini dilakukan untu } \\
\text { menguji keefektivan LKS. Uji } \\
\text { keefektivan LKS diperoleh dari } \\
\text { hasil penilaian pengamatan } \\
\text { aktivitas siswa yang dilakukan } \\
\text { oleh observer (pengamat) } \\
\text { dimana observer diminta untuk } \\
\text { mengisi lembar observer yang } \\
\text { telah diberiikan pada saat } \\
\text { penelitian dan hasil belajar } \\
\text { yaitu gabungan nilai setiap } \\
\text { hasil tes LKS dan nilai tes hasil } \\
\text { belajar siswa. Hasil pada tahap } \\
\text { ini adalah efektif berdasarkan } \\
\text { lembar pengamatan aktivitas } \\
\text { siswa dan hasil belajar. }\end{array}$ \\
\hline
\end{tabular}

Untuk uji efektivitas intrumen yang digunakan ada 2 macam yaitu sebagai berikut.

1. Intrumen lembar pengamatan aktivitas siswa.

Instrumen lembar pengamatan aktivitas siswa dibuat sebanyak 10 item pertanyaaan. Berikut kisi-kisi item instrumen pengamatan aktivitas siswa.

Tabel 2 Kisi-kisi Instrumen Pengamatan Aktivitas Siswa

\begin{tabular}{|c|l|}
\hline NO & \multicolumn{1}{|c|}{ Aspek Yang Diamati } \\
\hline 1 & Siswa mendengarkan penjelasan guru \\
\hline 2 & Siswa memperhatikan penjelasan guru \\
\hline 3 & $\begin{array}{l}\text { Siswa bertanya kepada guru atau } \\
\text { teman apabila ada hal yang tidak } \\
\text { dipahami }\end{array}$ \\
\hline 4 & $\begin{array}{l}\text { Siswa menjawab pertanyaan yang } \\
\text { diberikan guru atau teman }\end{array}$ \\
\hline 5 & $\begin{array}{l}\text { Siswa mengemukakan pendapat pada } \\
\text { saat diskusi }\end{array}$ \\
\hline 6 & $\begin{array}{l}\text { Siswa menjaga ketenangan di dalam } \\
\text { kelas }\end{array}$ \\
\hline 7 & $\begin{array}{l}\text { Siswa melakukan kegiatan belajar } \\
\text { sesuai dengan langkah-langkah di } \\
\text { dalam LKS }\end{array}$ \\
\hline 8 & Siswa membuat \\
\hline
\end{tabular}

\begin{tabular}{|c|lc|}
\hline NO & \multicolumn{2}{|c|}{ Aspek Yang Diamati } \\
\hline & $\begin{array}{l}\text { berdasarkan langkah-langkah pada } \\
\text { LKS }\end{array}$ \\
\hline 9 & $\begin{array}{l}\text { Siswa menjawab soal latihan pada } \\
\text { LKS }\end{array}$ \\
\hline 10 & Siswa aktif dalam berdiskusi \\
\hline
\end{tabular}

2. Hasil belajar

yaitu gabungan nilai latihan pada tahapan-tahapan penilaian LKS yang dikerjakan oleh siswa dan nilai tes hasil belajar siswa. Untuk soal pada LKS dengan menggunkan langkah- langkah pada CTL sedangkan tes hasil belajar (THB) dibuat sebanyak 5 soal dan di teskan di akhir pembelajaran pada semua LKS.

Analisis efektivitas dalam penelitian pengembangan ini adalah sebagai berikut.

a) Lembar Pengamatan Aktivitas Siswa

Lembar pengamatan aktivitas siswa dianalisis dengan menggunakan lembar pengamatan aktivitas siswa oleh obeserver (pengamat). observer mengisi penilaian terhadap LKS dengan penilaian berupa jawaban (1) tidak aktif, (2) kurang aktif, (3) cukup aktif, (4) aktif, (5) sangat aktif untuk setiap pertanyaan. Berikut tabel keriteria kefektivan LKS.

Tabel 3 kriteria keefektivan LKS

\begin{tabular}{|c|c|}
\hline Interval Skor & Kategori Keefektivan \\
\hline $4 \leq \bar{E} \leq 5$ & Sangat efektif \\
\hline $3 \leq \bar{E}<4$ & Efektif \\
\hline $2 \leq \bar{E}<3$ & Kurang efektif \\
\hline $1 \leq \bar{E}<2$ & Tidak efektif \\
\hline
\end{tabular}

(Diadopsi dari Maizora, 2011)

\section{b) Hasil belajar}

Hasil belajar siswa didapatkan dari gabungan nilai latihan pada tahapan-tahapan penilaian LKS yang dikerjakan oleh siswa dan nilai tes hasil belajar siswa. Dihitung dengan menggunakan rumus sebagai berikut

$$
\mathrm{KB}=\frac{N_{S}}{N} \times 100 \%
$$

Keterangan: $\mathrm{KB}=$ Ketuntasan Belajar

$N_{S}=$ Jumlah siswa yang mendapat nilai $\geq$ KKM

$\mathrm{N}$ = Jumlah siswa

Modifikasi dari Trianto (2010) 
Dan untuk menghitung Rataan ketuntasan belajar siswa dari hasil pengerjaan LKS dan tes hasil belajar pada pada uji coba efektivitas ditentukan oleh rumus sebagai berikut.

\section{Rataan Ketuntasan Belajar $=$}

$$
\frac{\text { ketuntasan belajar } L K S 1+L K S 2+L K S 3+T H B}{4}
$$

LKS dikatakan efektif jika ketuntasan belajar klasikal siswa diatas $75 \%$ artinya banyak siswa tuntas nilai diatas KKM $75 \geq$ $75 \%$.

LKS dikatakan efektif apabila:

1. Berdasarkan lembar pengamatan aktivitas siswa LKS dapat menunjukkan kategori efektif.

2. Untuk hasil belajar siswa Persentase rata-rata jumlah siswa yang memenuhi kriteria ketuntasan minimal (Ketuntasan Belajar Klasikal) adalah $\geq 75 \%$

\section{HASIL DAN PEMBAHASAN}

a. Efektif LKS berdasarkan lembar pengamatan aktivitas siswa.

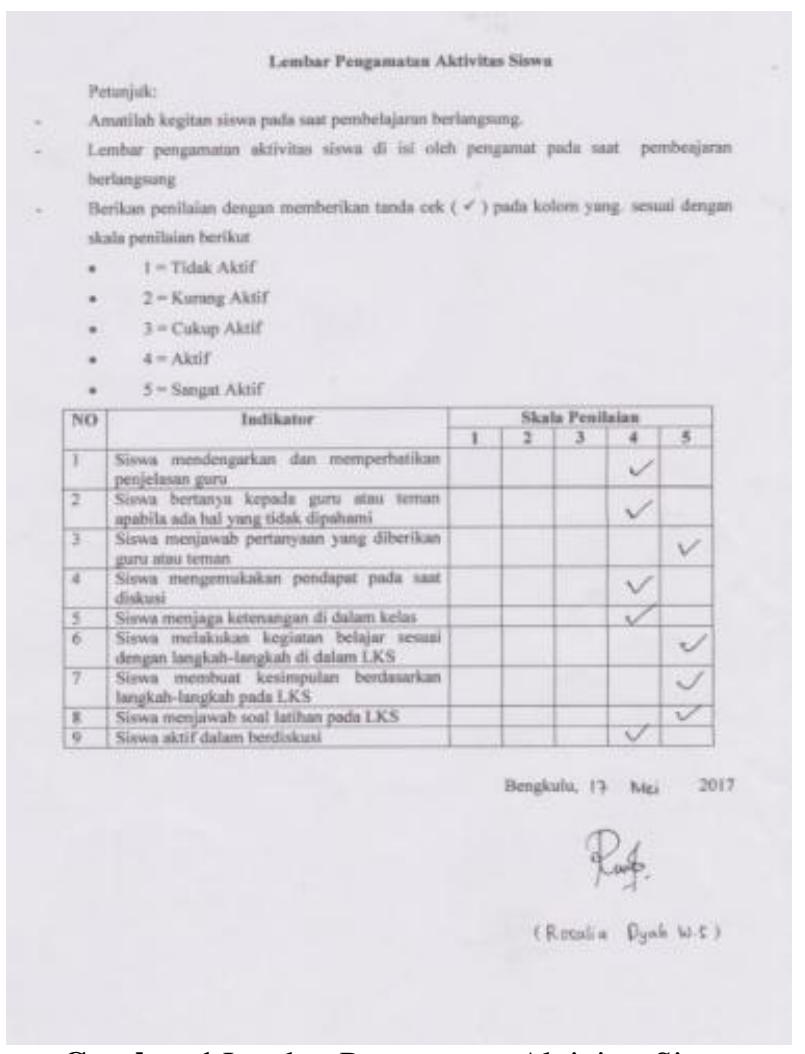

Gambar 1 Lembar Pengamatan Aktivitas Siswa
Aktivitas siswa dalam proses belajar mengajar dianalisis melalui hasil penilaian lembar aktivitas siswa, aspek pengamatan yang diamati oleh pengamat merupakan aktivitas terukur dan tertutup yang dilakukan oleh siswa melalui lembar angket. Skor aktivitas siswa dari pengamat akan menunjukkan tingkat aktivitas siswa selama pembelajaran berlangsung. Aktivitas siswa dalam proses belajar pada saat penelitian sesuai dengan tujuan yang ingin dicapai sesuai dengan pendekatan Contextual Teaching and Learning (CTL). LKS dikatakan efektivitas jika LKS berdasarkan lembar pengamatan aktivitas siswa menunjukkan kategori efektif pada uji efektivitas atau uji coba skala besar.

\section{b. Efektif LKS berdasarkan Hasil belajar}

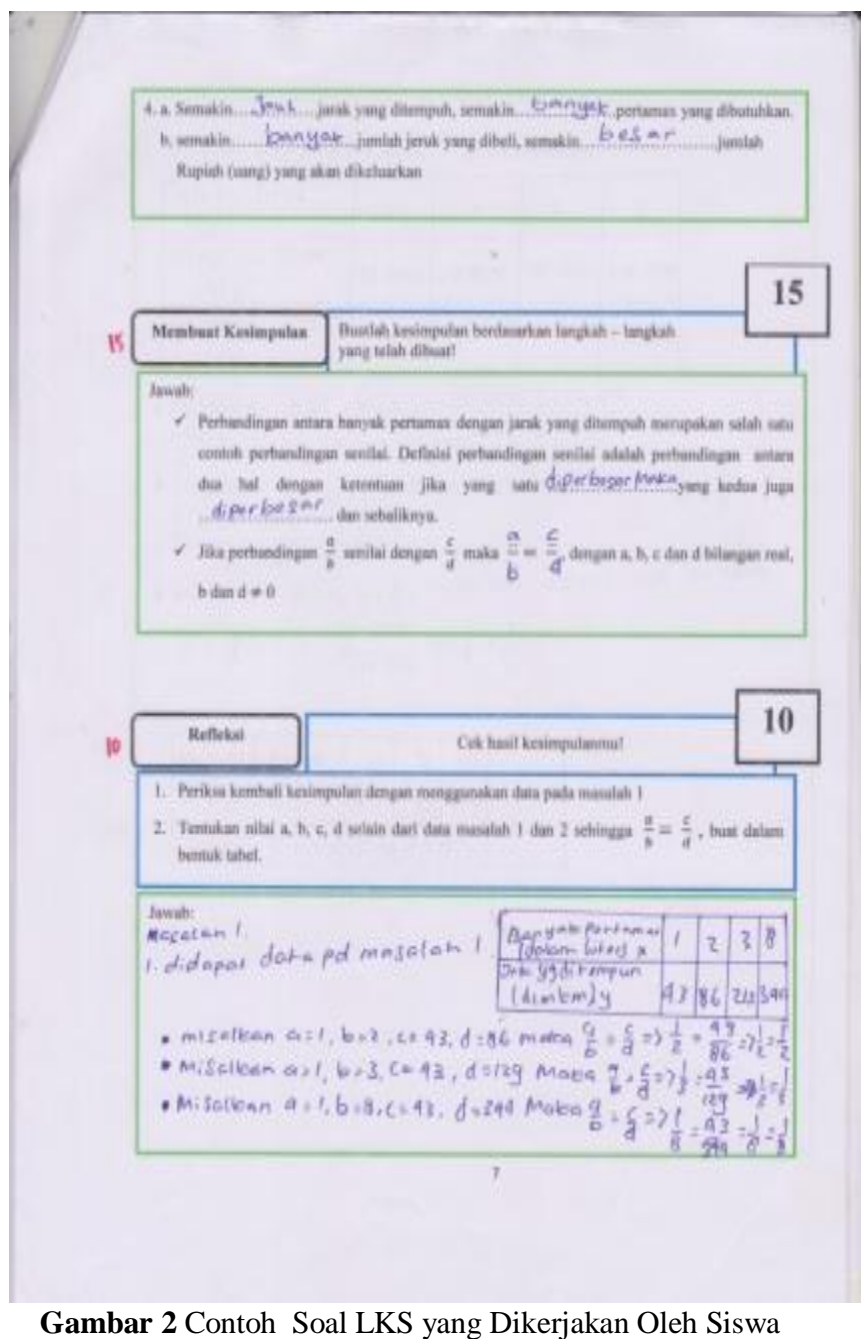

Gambar 2 Contoh Soal LKS yang Dikerjakan Oleh Siswa 


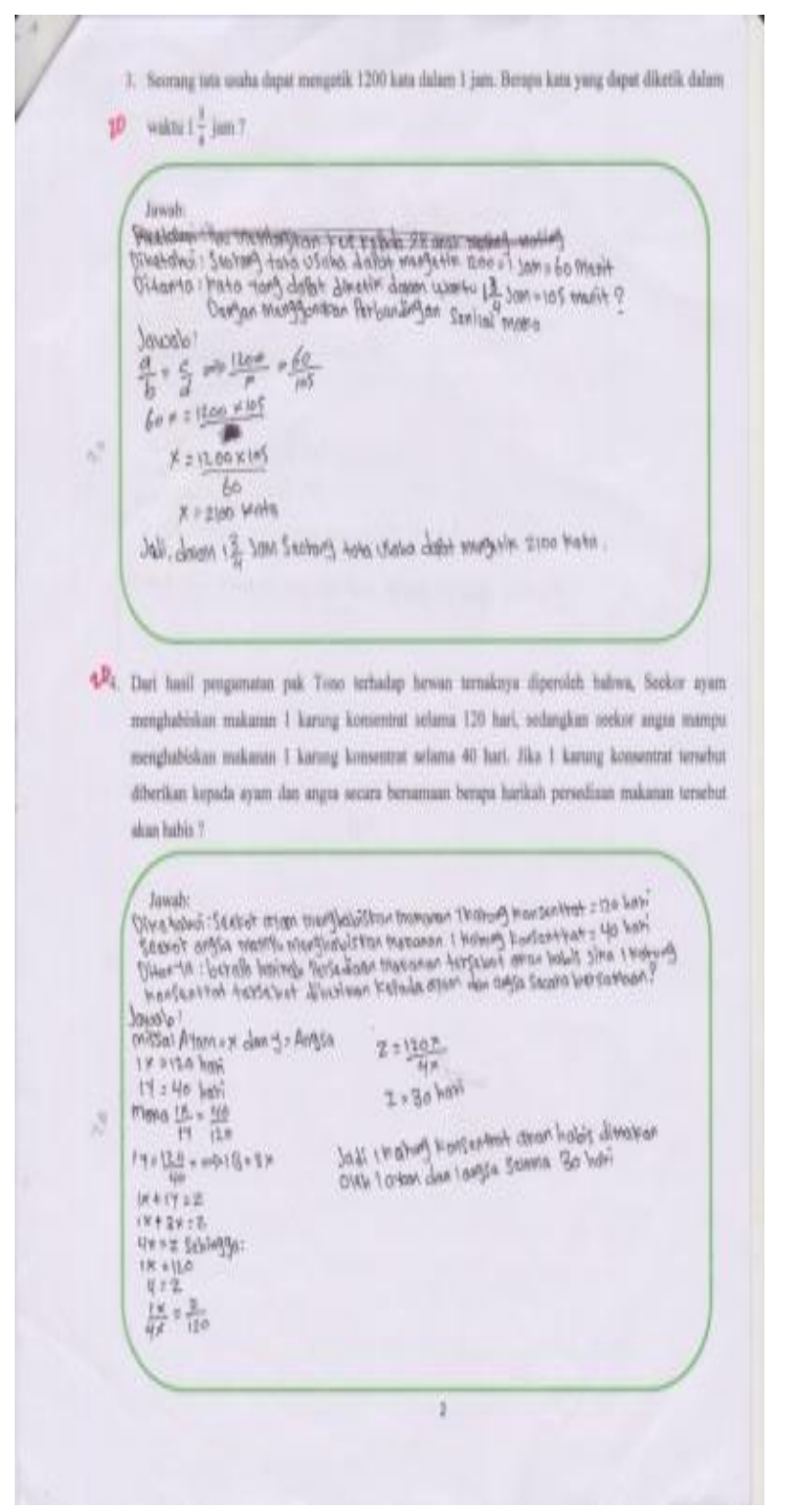

Gambar 3 Soal Tes Hasil Belajar (THB)

Pada LKS soal yang dibuat berdasarkan langkah-langkah yang ada pada CTL yaitu: a) mengidentifikasi masalah. b) membuat pertanyaan. c) membuat dugaan. d) menguji hipotesis. e) membuat kesimpulan. f) refleksi. g) assessment. Soal pada tes hasilmbelajar (THB) dibuat sebanyak 5 soal dimana soal tersebut mempunyai tipikal yang sama pada LKS. Dengan demikian uji efektifitas hasil belajar telah memenuhi kategori efektif.

\section{PENUTUP}

\section{Simpulan}

Kesimpulan dari penelitian ini adalah 3 LKS yang dikembangkan memenuhi kriteria efektif karena memenuhi : a. Lembar pengamatan aktivitas siswa menunjukkan efektif.

b. Nilai Hasil belajar setiap tes pada tahapan LKS dan tes hasil belajar telah memenuhi ketuntasan minimal.

\section{Saran}

Saran dari penelitian ini adalah sebagai berikut:

1. Supaya proses pembelajaran lebih efisien maka Evektivitas lembar kegiatan siswa (LKS) matematika berbasis pendekatan contextual teaching and learning (CTL) pokok bahasan perbandingan sebaiknya disesuaikan dengan alokasi waktu.

2. Harus adanya pokok bahasan yang berbeda dalam menggunakan pendekatan contextual teaching and learning (CTL) karena Berdasarkan respon siswa diketahui bahwa siswa sangat menyukai belajar matematika dengan menggunakan pendekatan contextual teaching and learning (CTL).

\section{DAFTAR PUSTAKA}

Prastowo, Andi. 2013. Panduan Kreatif Membuat Bahan Ajar Inovatif. Jogjakarta: Diva Press.

Depdiknas. 2008. Panduan Pengembangan Bahan Ajar. Jakarta: DEPDIKNAS

Komalasari, Kokom. 2013. Pembelajaran Kontekstual. Bandung: PT Refika Aditama.

Maizora, S. 2011. Pengembangan Web Pembelajaran Kalkulus Deferensial FKIP Universitas Bengkulu. Tesis tidak diterbitkan. Padang: Program PascaSarjana Univeritas Negeri Padang

Tim Puslitjaknov. 2008. Metode Penelitian Pengembangan. Jakarta: Depdiknas.

Trianto. 2013. Mendesain Model Pembelajaran Inovatif-Progresif. Jakarta: Kencana Prenada Media Group

Yamin, Martinis. 2011. Paradigma Baru Pembelajaran. Jakarta: Gaung Persada Press.

Lestri, Karunia Eka dan Yudhanegara, Mokhammad Ridwan. 2015. Penelitian Pendidikan Matematika. Ban dung: PT Refika Aditama. 